\title{
Online Road Traffic Accident Monitoring System for Nigeria
}

\author{
Adebayo Peter Idowu ${ }^{1}$, Kehinde Williams ${ }^{2}$ and Emmanuel Olonade ${ }^{1}$ \\ ${ }^{1}$ Department of Computer Science \& Engineering, Obafemi Awolowo University, Ile-Ife, Nigeria \\ ${ }^{2}$ Department of Physical and Computer Sciences, College of Natural and Applied Sciences, McPherson \\ University, Ajebo, Ogun State, Nigeria \\ ²kehindewilliams@yahoo.com
}

\begin{abstract}
The collection, management and dissemination of road traffic accident (RTA) related events has posed a serious problem to Nigerian road safety officers and all stakeholders alike. This is especially true because of the absence of a central repository from which all accident related information can be stored and managed. Where available, these information are available in paper based form and this poses a bottleneck in updating the available information. In this study, a Web based Road Traffic Accident Monitoring System (RTAMS) was developed for Nigerian.

The Road Traffic Accident Monitoring System (RTAMS) was developed using Adobe Dreamweaver and Notepad++ as the Integrated Development Environments, HTML, CSS and JavaScript were used for the frontend, PHP was used as the scripting language, and MySQL served as the database server. Most of the languages and tools used were open source which ensured that the application would be robust, reusable, cheap and highly scalable.

The result of the developed system shows that road safety officers, users, policy makers and all other stakeholders can be able to register, login, submit reports and run queries on information that has been previously entered into the system such as the accidents that occurred on a particular route or the accident in which an identified victim was involved. Policy makers can run these queries in order to take appropriate steps in minimizing road traffic accident occurrences.

In conclusion, this system will help create a paperless alternative to the present method of RTA information and thus make information dissemination quicker and also improve first aid response to accident occurrences.
\end{abstract}

Keywords: Road Accident, Traffic, Monitoring System, Vehicle

\section{Introduction}

Road traffic Accidents (RTA) is one of the major causes of mortality and morbidity around the world and it has been discovered that low and middle income countries are the most affected (Krug et al, 2000). The World Health Organization estimates that more than 3,000 people are killed every day in road traffic accidents globally, with at least 30,000 others injured or disabled. This adds up to over 1 million people killed and between 20-50 million injured or crippled in road traffic accidents each year (Krug et al, 2000). The increased rate of fatal road accidents worldwide has been attributed to increased motorization and explosion (WHO, 1984, Atubi, 2010); statistics indicate that over 90 percent of traffic accident situations in Nigeria can be attributed to driver errors (Aworemi et al, 2009). 
Motor vehicle crashes have also been discovered to be the leading cause of death in adolescents and young adults (Taket, 1986) and of the estimated 856,000 road deaths occurring annually worldwide, $74 \%$ are in developing countries (World Bank, 1990). While the proportion and absolute number of traffic fatalities have reduced by more than $20 \%$ in industrialized nations, a number of developing countries have experienced dramatic increases (Ross et al, 1991, Akinyemi, 2009). Nigeria and Kenya for instance have experienced a fivefold increase in traffic related fatalities over a period of 30 years of observation. Also it has been discovered that Asian and African countries, with relatively low vehicle densities, are experiencing substantially higher fatality rates per 10,000 vehicles than the industrialized European and North American Nations (WHO, 1984; Atubi, 2010).

The global costs of road traffic injuries are enormous, one report estimates the global costs of road crashes is about $\$ 518$ billion annually in US Dollars, and ranges in percentage of GNP (Gross National Product) from $0.3 \%$ in Vietnam to almost $5 \%$ of GNP in the USA and Malawi (Jacobs et al, 2000). In another report it is stated that traffic crashes impact the economy of developing countries at an estimated cost of $1-2 \%$ of a country's GNP per annum, as a result of mortality, morbidity, and property - related costs (WHO, 1989; Akinyemi, 2009).

Causes of motor vehicle crashes involve the interaction of multiple factors that include people, vehicles and the road environment. Human error is estimated to account for between $64 \%$ and $95 \%$ of all causes of traffic crashes in developing countries (Haddon, 1980; TRL, 1990, Atubi, 2010). A large number of old vehicles often carry more passengers than they are designed to carry and a lot of them lack safety belts and helmets; apart from these factors, poor road design and maintenance is a factor that contributes to the high rate of crashes in developing countries.

The major causes of road traffic accidents could be classified under three broad subheadings: vehicle-related factors, human-related factors, and environment related factors (Gungul, 2012). Vehicle - related factors include vehicle design, the vehicle body, the brake system, the vehicle tyres, the vehicle lights and the engine. Every vehicle is designed for a specific maximum load in all areas so it is no surprise that when it is subjected to stress above the provisions of the design specifications, accelerated wear and tear set into the vehicles (Gungul, 2012). The brake subsystem, working jointly with the accelerator synchronizes the speed of vehicles; any malfunctioning of the brake sub-system is to be taken as a potential source of accident. Also, when tyres are overinflated, thoroughly worn out or when there is failed indicator lights or non-existent headlights, accidents could occur. The sudden failure of the engine sub-system (which may be considered as the "brain" of the vehicle), if mismanaged could cause an accident even if an experience driver is at the helm (Gungul, 2012).

As regards Human-related factors, studies have clearly shown that the single most important contributing factor to road traffic accidents in Nigeria is the attitude of the driver to driving code and etiquette (Aworemi et al, 2009). Human-related issues include fatigue and sleepiness, faulty preparation, ignorance of highway codes or traffic orders, driving under the influence of drugs and/or alcohol, and inexperience.

Environmental factors contribute greatly to the rate of road accidents in Nigeria today and some of the well -known factors are fog, sunrays, mist and rain. Injuries especially road traffic injuries (RTIs) are linked to the environmental factors, also a significant number of vehicular accidents can be traced to the condition of the road. Recent studies have shown that the road is another major factor in road accidents in Nigeria (Asolor et al, 2008). Deficiencies of Nigerian roads are due largely to inadequate road design specification and maintenance (Akinyemi, 2009). Other significant factors 
Adebayo Peter Idowu, Kehinde Williams and Emmanuel Olonade; Online Road Traffic Accident Monitoring System for Nigeria, Transactions on Networks and Communications, Volume 3 No 1, Feb (2015); pp: 10-30

include the frequency of potholes on the roads, the indiscriminate location of police check points and the reluctance of the appropriate authorities to continually improve on the condition of the roads.

Engineering interventions are believed to be the most effective interventions for road traffic accidents (Peden et al, 2004). Improvement in road design, visibility, speed changes, are some such interventions, though their implementations requires information on areas with higher concentration of RTAs.

The aim of this paper is to develop a web-based road traffic accident monitoring system to replace the existing paper - based one. This monitoring system can be used by road safety officers to respond quickly to road accidents, to survey and record such occurrences, for other road traffic stakeholders to view records and for decision making bodies to make policies to reduce road traffic accidents.

\section{Road Traffic Accidents in Nigeria}

Statistics indicate that over 90 percent of traffic accident situations in Nigeria can be attributed to driver errors (Aworemi et al, 2009). Road accidents appear to occur regularly at some flash points such as where there are sharp bends, potholes and at bad sections of the highways. At such points over speeding drivers usually find it difficult to control their vehicles, which then result to fatal traffic accidents, especially at night (Atubi, 2009).

Cases of fatal road traffic accidents are reported almost daily on the major highways in Lagos State. Various categories of vehicular traffic are also involved in these fatal road traffic accidents in the state. Research in this area have focused on cases of road traffic accidents, collation of road traffic accident statistics and impact assessment of road safety campaign (Becker, 1996; Gozias et al, 1997 and Odero et al, 2003).

At the local level research in this area are concentrated on the effects of land use and human factors on road traffic accidents (Onokala, 1995). Motor vehicle crashes are the leading cause of death in adolescents and young adults (Taket 1986; Atubi and Onokala, 2009) and of the estimated 856,000 road deaths occurring annually worldwide, $74 \%$ are in developing countries (Atubi, 2000). Dramatic increases in the proportion and absolute number of traffic facilities have been witnessed in a number of developing countries, while they decreased by more than $20 \%$ in industrialised nations (Ross et al, 1991). In Nigeria (Oluwasanmi, 1993; Atubi, 2009b, 2009e and 2010c), a fivefold increase in traffic related fatalities was observed over the last 30 years.

African and Asian countries, with relatively low vehicle densities, are experiencing substantially higher fatality rates per 10,000 vehicles than the industrialised European and North American States (WHO, 1984; Atubi and Onokala, 2009).

In Nigeria, road traffic accident situation over the last three decades has been particularly disturbing. In 1976, there were 53,897 road traffic accidents resulting in 7,717 deaths. Although in 1981, the magnitude reduced to 5,114 accidents, but the fatality increased to 10,236 which mean that there was an average of 96 accidents and 28 deaths for everyday of that year (Ogunsanya, 1991; Atubi, 2000). The situation in subsequent years has not been any better. The number of people killed in road accidents between 1990 and 2005 rose from 28,253, and the fatality rate remains consistently high (Atubi, 2009). 
International comparison indicates that the chance of a vehicle killing someone in Nigeria is 47 times higher than in Britain (Atubi, 2009. The proportion of fatalities to injuries reported is also very high. For example, while Czech Republic has only one death in 175 accidents, France, one death in 175, South Africa, one death in 47 accidents, Nigeria has one death in 2.65 accidents (Atubi, 2010).

Various road safety strategies and counter measures have been used at different stages of network development. This method of seeking to prevent road accident mainly involves conscious planning, design and operations of roads. One of the most important factors in this method is the systematic identification and treatment of hazardous locations.

International comparison indicates that the chance of a vehicle killing someone in Nigeria is 47 times higher than in Britain. The proportion of fatalities to injuries reported is also very high. For example, while Czech Republic has only one death in 197 accidents, France one death in 175, South Africa, one death in 47 accidents, Nigeria has one death in 2.65 accidents (Atubi, 2010).

Road traffic accidents' statistics in Nigeria reveal a serious and growing problem with absolute fatality rate and casualty Figureure rising rapidly. In majority of developing countries, accident occurrence and related deaths are relative to either population or number of vehicles. Ironically, in Nigeria, studies have indicate that better facilities in terms of good quality and standardized roads have been accompanied by increasing number of accidents (Onakomaiya, 1988; Gbadamosi, 2002). This is totally contrary to the trends in countries were even the level of sophisticated road network and volume of vehicular traffic are much higher (Atubi, 2010).

In an effort to check this alarming trend, the Nigerian Federal Government inaugurated the Federal Road Safety Commission (FRSC) in 1988. The commission's functions include among others, the regular patrol of the highways with the aim of checking reckless driving.

\section{Related Literature}

Injuries are a major cause of mortality worldwide, causing more than five million deaths each year (Holder et al., 2001). As in many other areas of public health, major differences exist in countries' capacities for injury surveillance, generally corresponding to their overall economic development.

The Dutch Injury Surveillance System provides a basis for priority-setting in injury control in the Netherlands, for obtaining information on the direct medical costs of injury, and for identifying research priorities (Mulder et al., 2002).

Various states in the United States have their road traffic accident injury surveillance systems, a notable one among these is The State-wide Integrated Traffic Records System (SWITRS) used by the Department of Transport, California. SWITRS is a centralized accumulation of data for fatal and injury motor vehicle traffic accidents. In addition, a large proportion of the reported property damage only accidents are also processed into SWITRS. The reports are generated by over 500 city police departments, sheriff's offices and other local jurisdictions.

In Australia, the National Injury Surveillance Unit of the Australian Institute of Health and Welfare uses mortality statistics and hospital discharge data to produce reports on major causes of injury morbidity and mortality (Steenkamp, 2001), and the National Injury Surveillance Unit has worked in conjunction with injury surveillance and prevention practitioners in Australia to develop a set of national data standards for injury surveillance. In addition, Australia developed the National Coroners Information System, an Internet-based data storage and retrieval system for coroner cases. A state-based system, the Victorian Injury Surveillance and Applied Research System, accesses data 
Adebayo Peter Idowu, Kehinde Williams and Emmanuel Olonade; Online Road Traffic Accident Monitoring System for Nigeria, Transactions on Networks and Communications, Volume 3 No 1, Feb (2015); pp: 10-30

from death certificates, coroner records, hospital admissions, and emergency department visits to conduct state-wide surveillance of injury mortality and morbidity (Watson \& Ozanne-Smith, 2000).

In New Zealand, the Injury Prevention Research Unit was established in 1990 (Chalmers \& Langley, 1999). The Injury Prevention Research Unit uses data files on deaths and public hospital discharges from the National Minimum Data Set compiled by the New Zealand Health Information Service to publish fact sheets and results of descriptive and evaluative studies on priority injury prevention issues (Dow et al, 2001; Langley \& Smeijers, 1997; Smith \& Langley, 1998). The Injury Prevention Research Unit also maintains the National Injury Query System, an Internet-accessible, menu-driven source of information on injury mortality and morbidity statistics (National Injury Query System, 2000).

In The Global Burden of Disease, Murray and Lopez noted that "still very little is reliably known about causes of death in much of the developing world" (Murray \& Lopez, 1996). Although injury mortality and morbidity have been identified as major problems in some underdeveloped countries (Graitcer, 1992), injury surveillance is problematic because of the dearth of resources for public health activities in general. The World Health Organization and the CDC have recently developed a manual to help design, establish, and maintain injury surveillance systems, aimed in particular at persons working in settings with severe constraints on the capacity to keep records or assemble data into statistics (Holder et al., 2001).

In Asia, some countries have begun or are beginning to establish national systems for road injury surveillance. In other countries without such systems, surveys and studies have used existing data sets to describe and quantify data on important injury issues including road traffic injuries. Thailand initiated a provincial injury surveillance system in 1993, with reporting from five large hospitals located in Bangkok and four regions of the country. The data have been useful in documenting the large proportion of injuries from transport accidents and the large proportion of deaths occurring prior to hospitalization. The latter may indicate a need for improved prehospital transport and care. Hospital-based sentinel surveillance is being considered for a larger national injury surveillance system for the country (Santikarn, 1999).

While acknowledging this important limitation, a study in Uganda demonstrated the feasibility of a hospital-based system using a minimum data set and a simple standard index of injury severity (Kobusingye and Lett, 2000). The Caribbean Epidemiology Center of the World Health Organization is working with several member countries to develop emergency department-based injury surveillance. Recognizing the limited resources (money, personnel, etc.) available, the designers have emphasized simplicity, but they acknowledge that "even if the system is simple and flexible, sustainability will be difficult to achieve” (Ezenkwele \& Holder, 2001).

Other monitoring systems include the National Injury Mortality Surveillance System in South Africa, Transport Canada's National Collision Database (Canada), WreckWatch (White et al., 2008), OnStar (General Motors) and BMW's Automatic Crash Notification System.

BMW's Automatic Crash Notification System or GM's OnStar, notify emergency responders immediately by utilizing built-in cellular radios and detect car accidents with in-vehicle sensors, such as accelerometers and airbag deployment monitors. Sensors attached to the vehicle use a built-in cellular radio to communicate with a monitoring centre that is responsible for dispatching emergency responders in the event of an emergency. 
WreckWatch, a project undertaken through the collaboration of Virginia Tech and the University of Vanderbilt uses smartphones to measure the forces experienced by a vehicle and its occupants to provide a portable "black box" data recorder, accident detection system, and automatic emergency notification mechanism. (White et al., 2008).

\section{Methodology}

In order to develop the system, variables needed to develop a road traffic accident monitoring system were identified and reequired data were collected. The data were collected from the Osun State Sector Command of the Federal Road Safety Commission (FRSC) situated along the GbonganOsogbo expressway, Osogbo. The data collected includes information about the route, date of accident, description of the vehicle(s) involved, the cause of the accident, environment, collision type, nature of injury sustained by the affected road users, hospitals referred to, and health status.

In order to develop the prototype, an accident monitoring database would be developed using MySQL. In the process of developing the road traffic accident database, different tables, files, records and fields will be created. As a result, different road traffic accident factors such as the route, the date of the accident, description of the vehicle(s) involved, the cause of the accident, environment, collision type, nature of injury, hospitals referred, and health status will be stored in the database.

WampServer will be used to write MySQL queries for populating the database. The prototype will be implemented using Adobe Dreamweaver; Apache will be used as the web server to provide the basic functionality of the monitoring system. PHP will be used as a scripting language to program the server-side manipulation of the knowledge in the database. The model will be validated using data collected from the Federal Road Safety Commission (FRSC) office.

\subsection{Use Case Scenario for the Road Traffic Accident Monitoring System}

Use case scenarios were used to describe the interaction between users and the monitoring system. These use case scenarios were used to present the system requirements of the road traffic accident monitoring system that would make use of the developed data model. Using the scenarios afforded the opportunity to obtain the realistic description of the workflow of the system, which was to explicitly describe the intentions and actions of the users as in Jacobson (1992). The system requirements were presented with the use case scenarios to show how the road traffic accidents monitoring system would work in practice. The use case scenarios of the developed road traffic accident monitoring system are presented in Tables 1 , and 2 .

In the data insertion section of the developed road traffic accident monitoring system, road safety officers would be able to input the road accident information pertaining to a particular route into the system. Information such as route, collision type, crash severity, date, cause, distance from nearest hospital, and casualty/survivor count would be typed into the road traffic accident monitoring system.

In addition, the data query section of the road traffic accident monitoring system would allow users to perform various functions. One of such functions is that it allows viewing, editing, and deleting past accident records of the selected route. 
Table 1: Data Insertion Use Case

\begin{tabular}{l} 
Use Case Name \\
\hline Description \\
Actors \\
Pre-conditions \\
Scenario
\end{tabular}

Scenario

\section{Data Insertion}

Scenario to illustrate data insertion for road traffic accident monitoring User, Database Administrator

Click on hyperlink of a state followed by the desired route

1. System checks user identification

- If user is valid, system displays menu for entering accident details

- If user is not valid, the system prompts for user registration

2. User enters the details of the accident including the route, collision type, crash severity, date, cause, casualty/survivor count, and distance to the nearest hospital

3. Administrator inspects, modifies, views or deletes inserted entry

Table 2: Query Use Case for Road Traffic officers

\begin{tabular}{ll}
\hline Use Case Name & Data Query \\
\hline $\begin{array}{l}\text { Description } \\
\text { Actors }\end{array}$ & $\begin{array}{l}\text { Scenario to illustrate data query for road traffic accident monitoring } \\
\text { User, Database Administrator } \\
\text { Click on hyperlink of a state followed by the desired route } \\
\text { Scenario }\end{array}$ \\
$1 \quad \begin{array}{l}\text { System checks user identification } \\
\text { If user is valid, system displays menu for entering accident } \\
\text { - If user is not valid, the system prompts for user registration }\end{array}$ \\
$2 \begin{array}{l}\text { User can view, modify, or delete entries captured for accidents on a } \\
\text { selected route. } \\
\text { User can generate monthly and annual reports of reported accident } \\
\text { occurrences }\end{array}$ \\
\hline
\end{tabular}




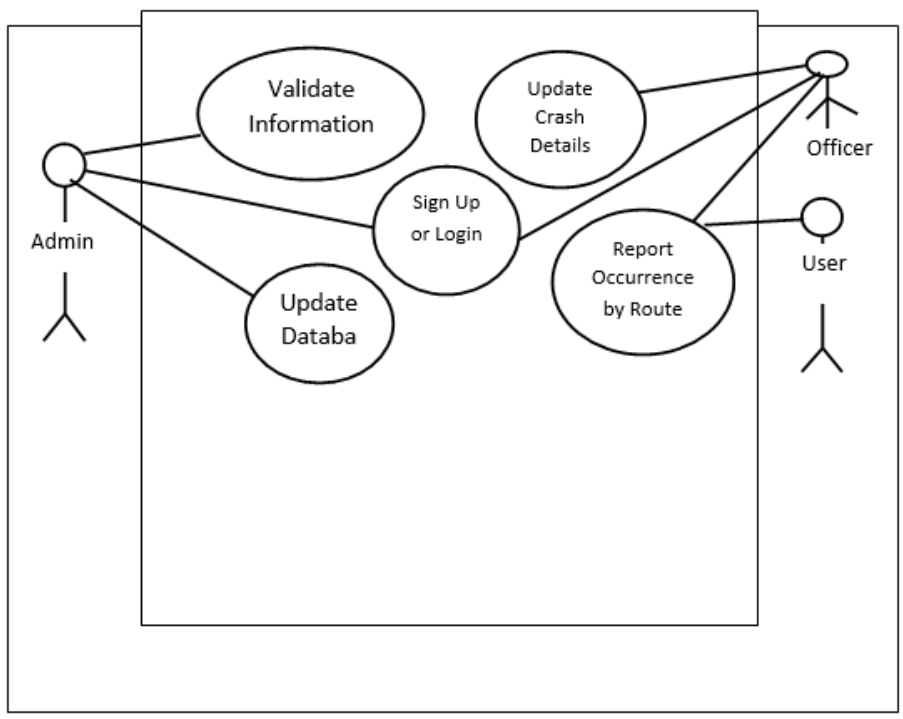

Figure 1: The Data Insertion Use Case

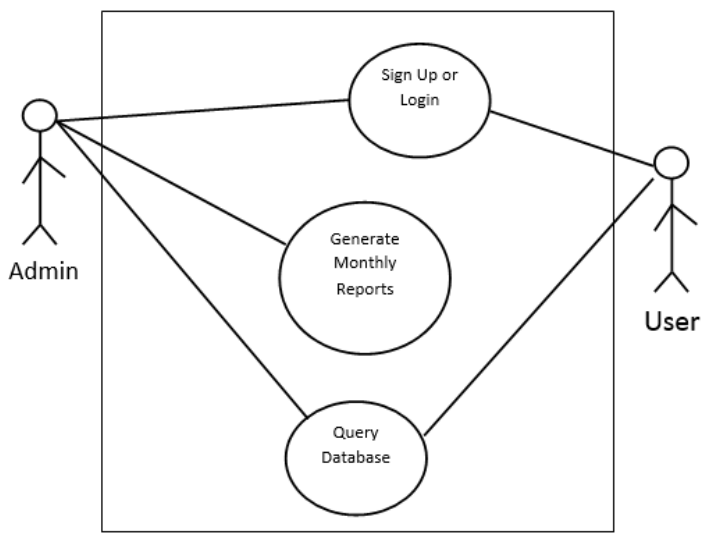

Figure 2: The Data Query Use Case

In the design of this system, there is need for a system architecture. In the developed road traffic accident monitoring system, there is need to make the design of the system easy, flexible and portable as much as possible. This was needful in order to allow users to easily make use of internet enabled mobile phones, tablets and other mobile devices, laptops, and desktop computers with web browsers to access the developed system.

The client-server system architecture was used and it is the thin client-server architecture. The road traffic monitoring system has two components namely: The server side and the client side. In the client approach almost all the work is done on demand at the server end and the client's task is to display data and information on the screen. In the thin client-server architecture, the web browser is the client.

The architecture was used because with it users will not be required to install any software on their systems. This is because a standard web browser often comes bundled with most operating systems and almost all current internet enable mobile phones and high end smartphones.

Clients would also not be required to have very powerful computer systems or mobile devices; however, the servers will require computer systems with higher configureuration for optimal performance. This is important as it would be regularly subjected to heavy computing tasks. There will be HTTP server and database server. Figure 1 depicts the road traffic accident monitoring system architecture. 
Based on the developed system, road safety officers can make use of even mobile devices to log in to add, modify, delete or view data in the developed road traffic accident monitoring system.

\subsection{The System Architecture}

In the design of the system, the use of a system architecture is highly important. The design was made to be as flexible, portable and easy to use as possible. This will make it possible for users with internet-enabled mobile phones or smartphone as well as users of desktop and laptop computers to access the system.

In the Road Traffic Accident Monitoring System (RTAMS), the thin client-server architecture was used. The thin client-server architecture makes us of the Web browser as the client. This architecture makes it possible to use any internet-enabled device with a Web browser to access the system; this is in order to ensure that the system is easily available and yet cheap to implement. In this architecture, most of the processing duties is assigned to the server; the client's duty is to display the processed data and information on the screen, which in this case is the Web browser.

This RTAMS system supports a database, business logic and user interface as the major areas of design. The User Machine is the device used to access the pages and forms used for the web application, e.g. phones and personal computers etc. The Web Server is the program which allows the application to run and behave as though it is hosted on the internet, e.g. WAMP server, XAMPP, Apache etc. The Back-End is the web server and the database management system (DBMS) that holds and manages the data pool used by the application. The PHP Script controls the exchange of data between the front-end and the application back-end.

The road safety officer on the road, upon having an accident alert, immediately relays road traffic accident related information to the officer in the office so that immediate action could be taken. Also, the Road users play a very important role as they also submit accident reports by submitting reports on the RTAMS website.

Finally, based on the information available in the system, the policy makers, who usually are government officials can make rules and regulations that affect road users and all other stakeholders.

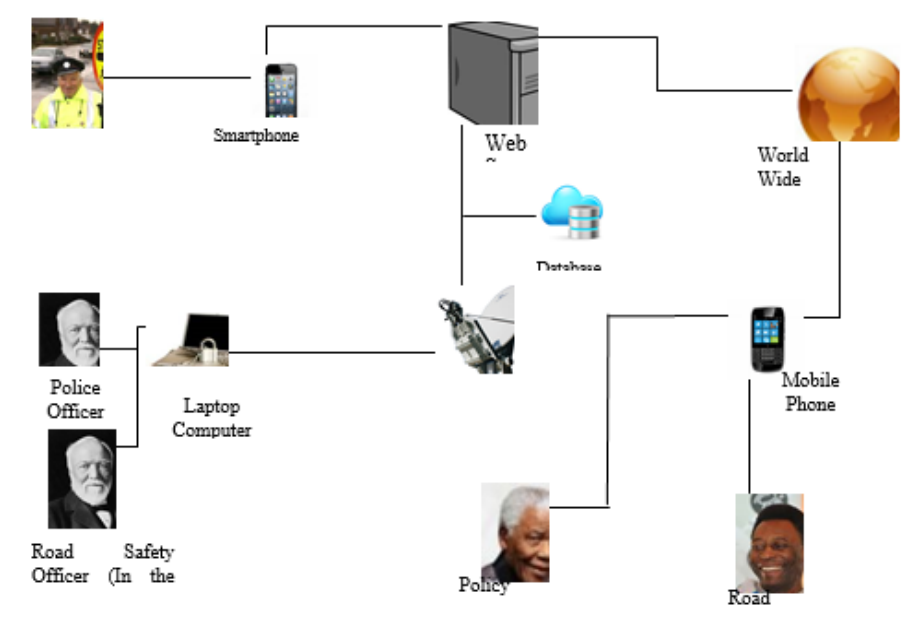

Figure 3: The System Architecture 


\section{Prototype Implementation}

The user interface allows the user to navigate the system and also facilitate interact with the database. The system is simple and user friendly through the use of Windows Interface Menu (WIMP), and pointing devices which is very important in computer graphics design and architecture. Hence, the road tracking information system was designed to accommodate users with varying skills and competence in the area of computer usage. So with the employment of WIMP paradigm and the use of pointing devices and graphical icon that represents the specific task that the user may want to perform, makes the system easy and convenient for all. A well designed and simple user interface provides user with a better understanding of the system.

\subsection{The Homepage}

This part of the user interface holds all the navigations of the application. This index page contains links to help existing users of the Road Traffic Accident Monitoring System (RTAMS) to log in and new users to register. There are also news relating to road safety and accident prevention on the homepage. On the homepage, the user is able to submit accident report, new users are able to register and returning users are able to login.

\subsection{The Registration Page}

On the Report page, the intended user of the system is required to provide his/her username, password, Full name, phone number and email address. Upon entering these details, the data will be sent into the database. All fields are required for successful registration and if one field is left empty, a prompt will come up.

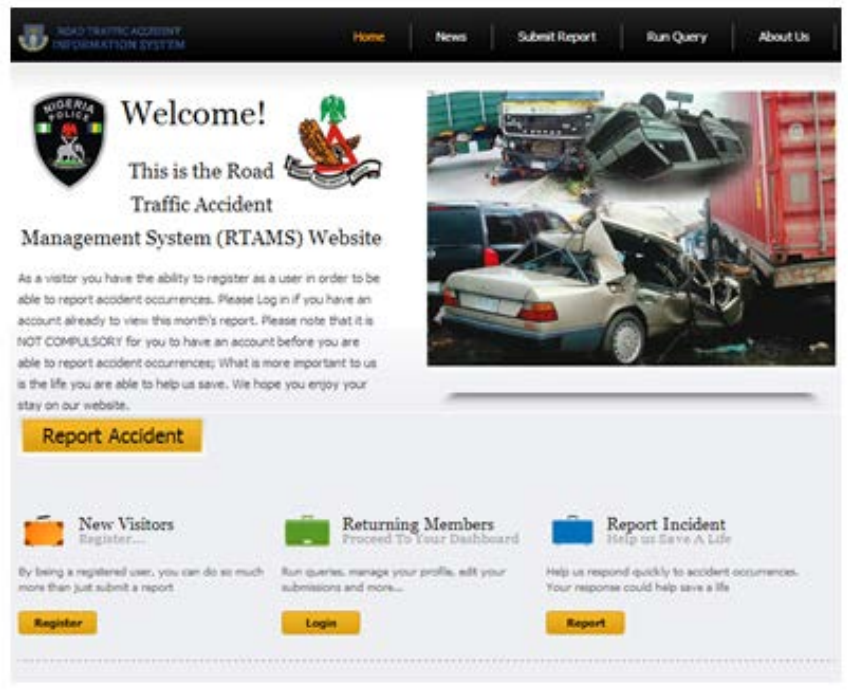

Figure 4: The RTAMS Homepage

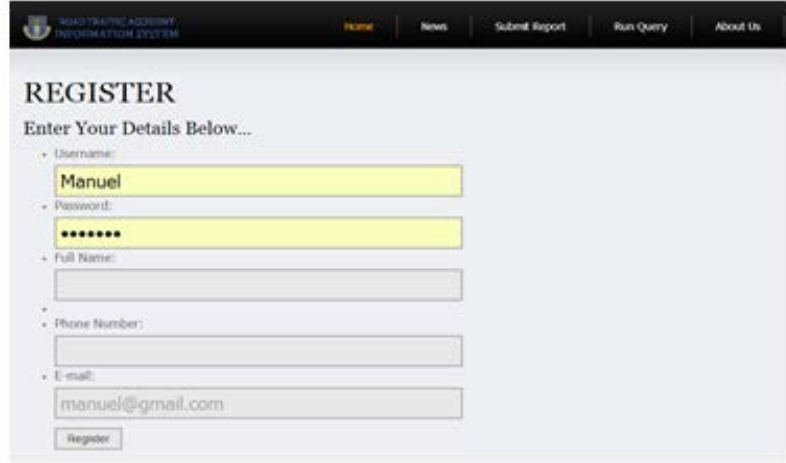


Figure 5: The Register Page

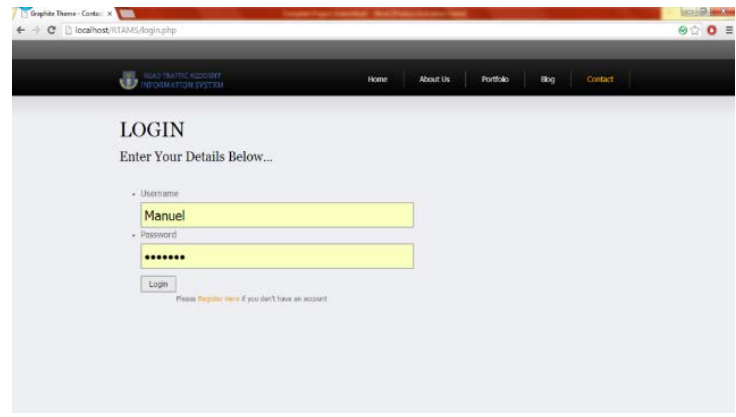

Figure 6: The RTAMS Login Page

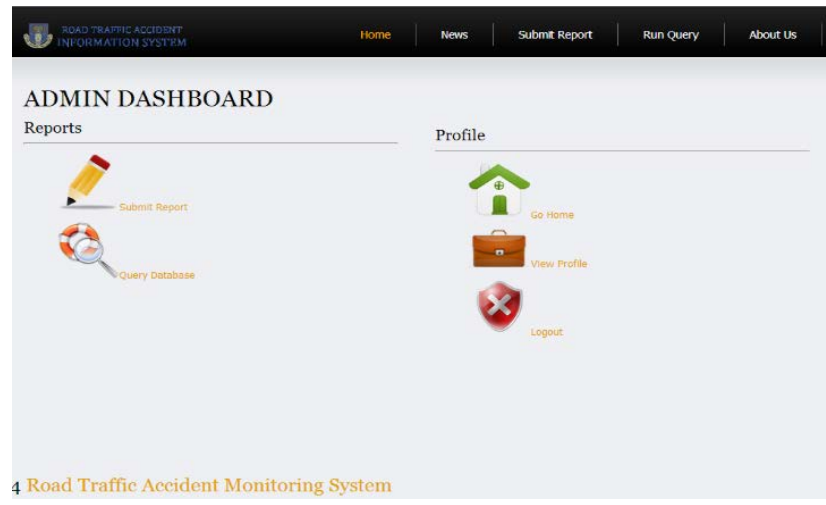

Figure 7: Admin Dashboard

\subsection{The Login Page}

When the user of the system encounters the login page, he will be required to enter his username and his password to be able to log into the system. For a login attempt to be successful, the username and password combination input by the user must correspond to values that are available in the database.

\subsection{The Admin Dashboard Page}

On the Admin Dashboard Page, the user has the ability to submit a report, query the database, view profile, go to the homepage or logout.

\section{5 “Report Accident" Page}

The report page allows the user to interact with the site administrator by reporting the current state of victims and property involved in an accident as he travels along a particular route. This report is therefore sent to the incidence table of the data base, where it is checked and validated by the administrator and then updated into the various fields of the data base for appropriate report generation.

The road's users are allowed to also report the accident occurrences on a particular road at any point in time. The road user can also make reports even if he does not have an account. The user clicks on the "Chat with Officer" link on the homepage and starts a chat with an office; he will be required to enter his name, his phone number, e-mail address and the description of the accident. This information is sent to the database where it will be validated by the administrator and finally updated. Below are screenshots of the Road Traffic Accident Monitoring System (RTAMS). 


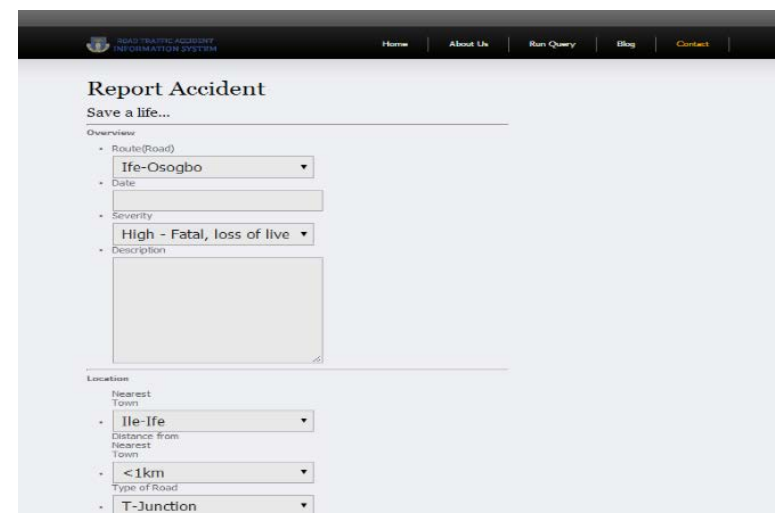

Figure 8: The Report Submission Page
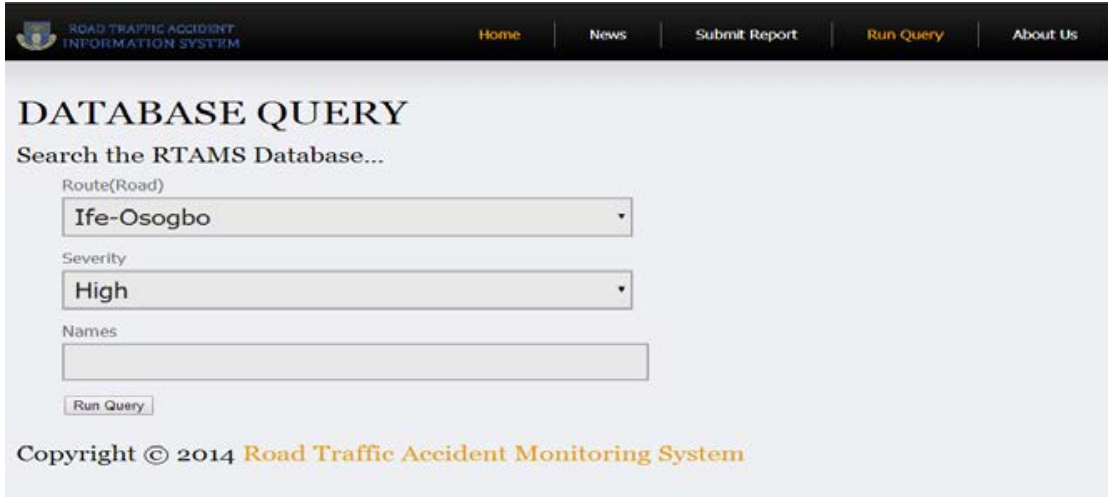

Figure 9: The Database Query Page

\subsection{The Database Query Page}

The user of the system has the ability to query the system based on three variables - The route (IfeOsogbo, Osogbo-llesa or llesa-Ife route), severity (High, medium, or low) and Names (which would be entered in the textfield).

\subsection{The Individual Report Page}

This page gives information about individual accident reports based on location (Nearest town, distance from nearest town, type of road, road surface condition, weather condition, light condition), vehicle information (vehicle type, number plate, vehicle condition, and vehicle colour), Accident Details (Date of Occurrence, Vehicle count, Total Victim count, uninjured victim count, injured victim count and dead victim count). Also, details about identification documents that were found at the accident scene are also entered on this page and finally, details that pertain to first aid (nearest town, nearest hospitals, and types of injuries) will also be entered on this page.

\subsection{Contact Page}

On the contact page, any user with complaints or information can use this page to send message to the system administrator or to road safety officers. The sender is required to enter his name, email address, the subject of the message and the message body. 

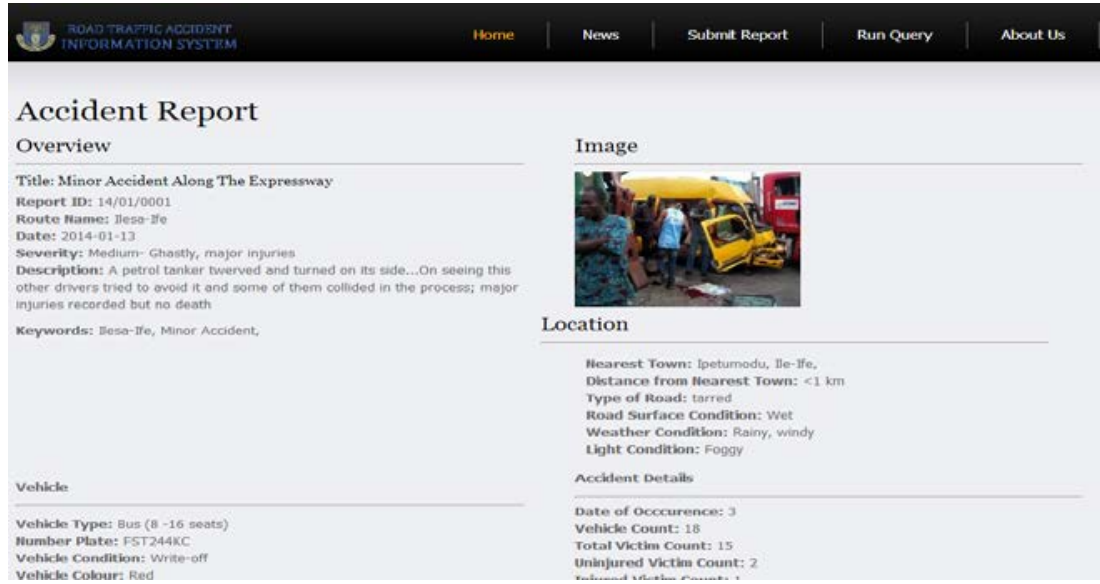

Figure 10: The Accident Report Page

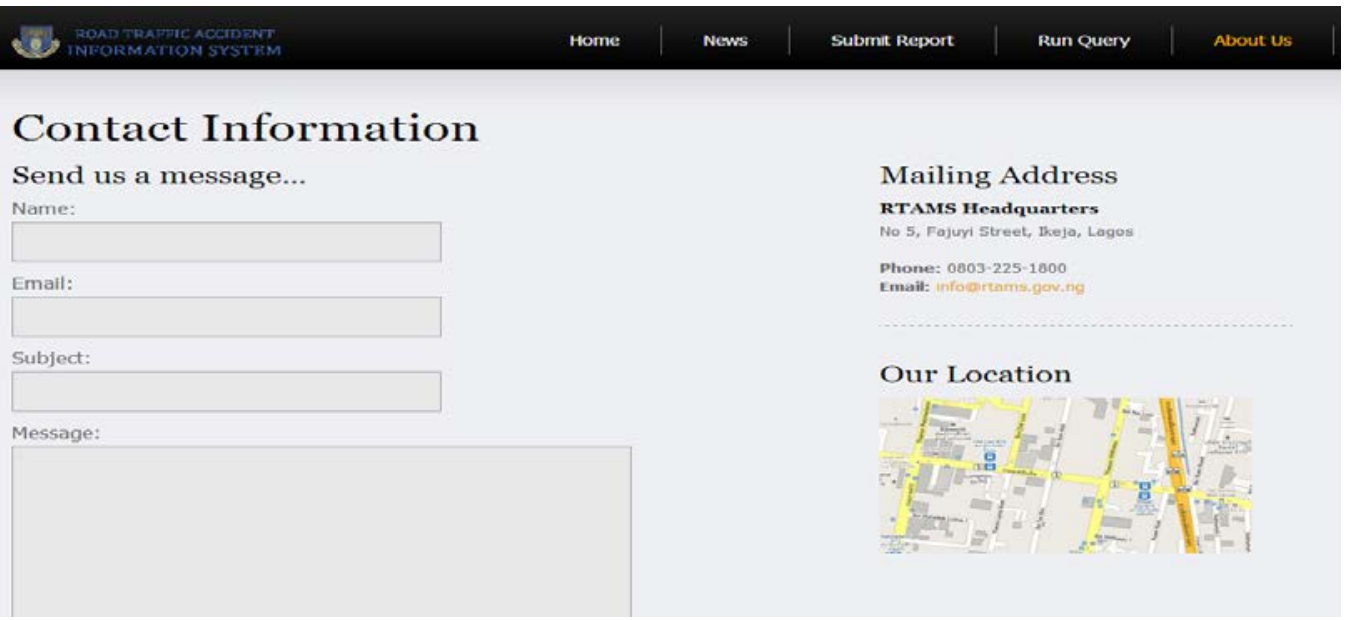

Figure 11: Contact Page

\section{Conclusion}

This paper focuses on the monitoring of road traffic accident occurrences in order to derive useful data such as the severity of the accident, the types of vehicles and victims involved in the accidents, the type of injuries sustained (in order to facilitate adequate first aid preparations), the condition of the road, the weather condition, the light condition and any form of identification detail gotten from the accident scene.

This paper shows an effective way of monitoring road traffic accident information which is a semiautomatic monitoring system in that it requires human interactions in the area of data and observation collection and updating of the database.

\section{REFERENCES}

[1] Akinyemi, E. O. (2009). Contributing Road Factors in Accidents on Rural Roads in Nigeria, in Road Traffic Accidents in Developing Countries Vol. I Asalor, Onibere and Ovuworie - eds, Joja press, Lagos.

[2] Alban (2011) War on the Roads. Basic Medical Journal. Vol. 324, No. 7346. 
[3] Allaramu, (2011) "Further Research on Accident Rates in Developing Countries". Accident Analysis and Prevention. Vol. 18, No. 2, pp. 119-127.

[4] Amber (2003). Accident Mortality and Morbidity in Developing Countries. In Manciaux M. and Romer, C.J. (ed) Accidents in Childhood and Adolescence: The Role of Research, Pp. 31-38. Geneva: World Health Organisation.

[5] Annest, J.L., Pogostin, C.L. (2000) CDC's short version of the ICECl. International classification of external causes of injury: a pilot test. Report to the World Health Organization collaborating centers on the classification of disease. Atlanta, GA: Office of Statistics and Programming, National Center for Injury Prevention and Control, Centers for Disease Control and Prevention, 2000. (http://www.cdc.gov/ncipc/pubres/icecibk.pdf).

[6] Asalor, J. O. (2010). Towards Improved Road Safety in Nigeria. Technical Report No. Rts/00/82/011, Faculty of Engineering, Uni of Benin.

[7] Atubi, A.O. (2010) Spatial and Temporal Perspective on Road Traffic Accident variations in Lagos mainland, South Western Nigeria. African Research Review,Vol.4 (1) pp.256-272.

[8] Atubi, A.O. (2010) Road Transport System Management and Traffic in Lagos, South Western Nigeria, Journal of African Research Review.Vol. 4. No.4. Pp. 459-470.

[9] Atubi, A.O. (2012) Determinants of road traffic accidentoccurrences in Lagos State: Some Lessons for Nigeria. International Journal of Humanities and Social Science. Vol. 2, No. 5, Pp. 225-343.

[10] Atubi, A.O. (2012) Epidemiology of Injuries from Road Traffic Accidents in Lagos State, Nigeria. International Journalof Science and Technology, Vol. 1, No. 2, Pp. 56-75.

[11] Atubi, A.O. and Onokala, P.C. (2009) Contemporary Analysis of Variability in Road Traffic Accidents in Lagos State, Nigeria. Journal of African Geographical Review. Vol. 28, Pp. 11-41.

[12] Atubi, A.O.(2009) Modelling Road Traffic Accidents in Lagos State, South Western Nigeria. Journal of Society and StateVol. 1. Nos 1 \&2, pp 57-74.

[13] Aworemi, A. and Alawode, E.C. (2009) Roads to where? Newswatch, December 30, 17 (13) 3.

[14] Balogun (2001) "Innovative Options for Financing Transport Infrastructure in Nigeria" In Nisereel, The Magazine of the Nigerian Institute of Social and Economic Research, NDS485, Ibadan

[15] Blandford, A., and William Wong, B.L. (2004) Situation awareness in emergency medical dispatch. International Journal of Human-Computer Studies, 61(4):421-452,. 
[16] Blond, L., Hansen, L.B. (1999) Injuries caused by falling soccer goalposts in Denmark. Br J Sports Med 1999;33:110-13

[17] Central Bank of Nigeria (1994) Annual Report and Statement of Account for the Year Ended 31 December, 1993. C.B.N., Lagos April.

[18] Central Bank of Nigeria (1997) Annual Report and Statement of Account for the Year Ended 31 December, 1996. C.B.N., Lagos April.

[19] Centre for Black Culture and International Understanding (2011) Osun State in Brief http://www.centreforblackculture.org/osunstate.htm. Retrieved 17th June 2013.

[20] Chalmers, D.J, Langley, J.D. (1999) New Zealand's injury prevention research unit: helping shape injury prevention policy and practice. Inj Prev 1999;5:72-5.

[21] Committee on Environmental Epidemiology National Research Council. (1997) Injury in America-a continuing public health problem. Washington, DC: National Academy Press.

[22] Conallen (2004). Driver Training of Africa: the UN-ECA Driving Manual. Proceedings of the Second African Road Safety Congress. Oslo: Institute of Transport Economics (TOI).

[23] Department of Health and Children. EHLASS report for Ireland 2000. Dublin, Ireland: European Home and Leisure Accident Surveillance System. (http://europa.eu.int/comm/health/ph/programmes/injury/outcome2000/fp_injury_ 2000_exs_19_en.pdf).

[24] Dimitrijevic et al., (2007). Road accidents and traffic flows: An econometric investigation. In Economica 67, pp 101-21.

[25] Dow NA, Stephenson SCR, Allnatt DM. Trends in thermal injury. Burns from fire or flames. Dunedin, New Zealand: Injury Prevention Research Unit, University of Otago, 2001. (Fact sheet no. 21) (http://www.otago.ac.nz/IPRU/FactSheets/FactSheet21.pdf).

[26] Dow, N.A, Stephenson, S.C., Casey, D.M. (2001) Injury to children in New Zealand resulting in death or hospitalization. Dunedin, New Zealand: Injury Prevention Research Unit, University of Otago, (Fact sheet no. 22) (http://www.otago.ac.nz/IPRU/FactSheets/FactSheet22.pdf).

[27] Endsley, M.R. (1995) Toward a theory of situation awareness in dynamic systems. Human Factors: The Journal of the Human Factors and Ergonomics Society, 37(1):3264.

[28] E-Nigeria (2011) About Osun State http://www.e-nigeria.net/osun.html. Retrieved 17th June 2013 
[29] European Union Road Federation, ERF (2001) Comparative Accident Costs in Developing Countries. TRRL Supplementary Report 206. Crowthorne: Transport and Road Research Laboratory.

[30] Expert Vanguard (2011). Work and health country profiles: Country profiles and national surveillance indicators in occupational health and safety (People and Work Research Reports 44).

[31] Ezenkwele, U.A, Holder, Y. (2001). Applicability of CDC guidelines toward the development of an injury surveillance system in the Caribbean. Inj Prev; 7:245-8.

[32] Ezenwa, A.O. (1986) "Prevention and Control of Road Traffic in Nigeria" Journal of the Royal Society of Health. Vol. 106, No. 1, Pp. 25-26.

[33] Federal Road Maintenance Agency (2001) An Empirical Investigation into Nigeria Road Accident Causation Factors Annual Report and Statement of Account

[34] Filani, M.O. and Gbadamosi, K.T. (2007) Spatial and Temporal Pattern of Road Traffic Accident Occurrences in Nigeria: 1970-1995. Nigerian Geographical Journal, Vol. 5, No. 1, Pp. 55-70.

[35] Fingerhut, L.A, Cox, C.S, Warner, M. (1998) International comparative analysis of injury mortality. Findings from the ICE on injury statistics. International Collaborative Effort on Injury Statistics. Adv Data; (303):1-20.

[36] Foster, Warren G., Agzarian, John (2006). "Reporting results of biomonitoring studies". Analytical and Bioanalytical Chemistry 387 (1): 137-40. doi:10.1007/s00216006-0822-6. PMID 17093961.

[37] Fouracre, P. R. and Jacobs, G.D. (1976) Comparative Accident Costs in Developing Countries. TRRL Supplementary Report 206. Crowthorne: Transport and Road Research Laboratory.

[38] Gbadamosi, K.T. (1994) "Spatial Analysis of Road Accidents in Nigeria, 1970-1990" Unpublished M.Sc. Thesis, Ogun State University, Ago-Iwoye, Nigeria.

[39] Graitcer, P.L. (1992) Injury surveillance in developing countries. MMWR CDC Surveill Summ; 41:15-20.

[40] Gungul, T. (2012). Road Traffic Accidents in Nigeria: Causes and Control, Journal of Applied Science and the Environment, Vol 3, pp 25-29.

[41] Haddon, W. (1980) Advances in the Epidemiology of Injuries as a basis for public policy. Public Health Reports. 95: pp. 411-421.

[42] Harrald, J. and Jefferson, T. (2007) Shared situational awareness in emergency management mitigation and response. In System Sciences, 2007. HICSS 2007. 40th Annual Hawaii International Conference on, page 23. IEEE. 
[43] Hoberman (2009). An Exploratory Simulator Study on the Use of Active Control Devices in Car Driving. TNO-Report IZF 1992 B-2., TNO Institute for Perception. Soesterberg, The Netherlands.

[44] Holder, Y., Peden, M., Krug, E, et al, eds. (2001) Injury surveillance guidelines. Geneva, Switzerland: World Health Organization,. (Document no. WHO/NMH/VIP/01.02) (http://www5.who.int/violence injury prevention/download.cfm?id=0000000136).

[45] Injury Section, Population and Public Health Branch, Health Canada. 2003 Injury surveillance on-line. Tunney's Pasture, Ottawa, Canada: Canadian Hospitals Injury Reporting and Prevention Program, Health Canada. (http://www.hc-sc.gc.ca/pphbdgspsp/publicat/chirpp-schirpt/index.html ).

[46] International Collaborative Effort (ICE) on Injury Statistics. Injury ICE activities. Hyattsville, MD: National Center for Health Statistics, Centers for Disease Control and Prevention, 2002. (http://www.cdc.gov/nchs/about/otheract/ice/projects.htm ).

[47] Jacobs, G.D.; Aaron - Thomas, A; Astrop, A. (2000) Estimating Global Road Facilities. Crow Thorne, U.K. Transport Research Laboratory Report 445. Pp. 1-35.

[48] Jacobs, G.D. and Sayer, I.A. (1983) Road Accidents in Developing Countries'. Transport and Road Research laboratory, TRRI Supplementary Report 897 Crowthorne.

[49] Jacobson (1992). Estimating Global Road Facilities. Crow Thorne, U.K. Transport Research Laboratory Report 445. Pp. 1-35.

[50] Keuffel (1996). Finnish occupational exposure databases. Applied Occupational and Environmental Hygiene, 16(2), 154-158.

[51] Kobusingye, O.C, Lett, R.R. (2000) Hospital-based trauma registries in Uganda. J Trauma; 48:498-502.

[52] Krug, E.G., Sharma, G.K.; Lozano, R. (2000). The Global Burden of Injuries. American Journal of Public Health. 90(4); 523-526.

[53] Langley, J.D., Smeijers, J. (1997) Injury mortality among children and teenagers in New Zealand compared with the United States of America. Inj Prev; 3:195-9.

[54] Langley, J.D. (1995) Experiences using New Zealand's hospital based surveillance system for injury prevention research. Methods Inf Med; 34:340-4.

[55] Le, L., Pham, C., Linnan M., et al. (2002) Vietnam profile on traffic-related injury: facts and Figure from recent studies and their implications for road traffic injury policy. Presented at the Road Traffic Injuries and Health Equity Conference, Cambridge, Massachusetts, April 10-12, 
[56] Li G.H., Baker S.P. (1991) A comparison of injury death rates in China and the United States, 1986. Am J Public Health 81:605-9.

[57] Lu and Lu (2004). Motor Vehicle Injuries in Taiwan. Asia Pacific Journal of Public Health, 4:72-75.

[58] Lyons, R. A., Brophy, S., Pockett, R., et al. (2005). Purpose, development and use of injury indicators. Int J Inj Contr Saf Promot 12(4): 207-11

[59] Mackenzie SG, Pless IB. (1999) CHIRPP: Canada's principal injury surveillance program. Inj Prev; 5:208-13.

[60] Mattord, Verma (2008). Principles of Information Security. Course Technology. pp. 290-301. ISBN 978-1-4239-0177-8.

[61] Medical Research Council and UNISA. (2007). A profile of fatal injuries in South Africa 7th Annual Report of the National Injury Mortality Surveillance System 2005.MRC/UNISA Crime, Violence and Injury Lead Programme, July 2007.

[62] Mock CN, nii-Amon-Kotei D, Maier RV. (1997) Low utilization of formal medical services by injured persons in a developing nation: health service data underestimate the importance of trauma. J Trauma; 42:504-11.

[63] Mohan, P., Padmanabhan, V.N., and Ramjee, R.. (2008) Nericell: Rich monitoring of road and traffic conditions using mobile smartphones. In Proceedings of the 6th ACM conference on Embedded network sensor systems, pages 323-336. ACM New York, NY, USA.

[64] Mulder S. (2001). Surveillance and priority-setting: where to start in preventing home and leisure accidents? Ridderkerk, the Netherlands: Ridderprint.

[65] Mulder, S., Blankendaal, F., Vriend, I., et al. (2002). Epidemiological data and ranking home and leisure accidents for priority-setting. Accid Anal Prev; 34:695-702.

[66] Murray, C.J., Lopez A.D, eds. (1996) The global burden of disease: a comprehensive assessment of mortality and disability from diseases, injuries, and risk factors in 1990 and projected to 2020. Geneva, Switzerland: World Health Organization.

[67] Mutabazi, (2011) Equity Dimensions of Road Traffic Injuries in low and Middleincome countries. Injury Control and Safety prevention. 10(1-2): 13-20.

[68] Najm, W. G., Sen, B., Smith, J. D., \& Campbell, B. N. (2003). Analysis of Light Vehicle Crashes and Pre-crash Scenarios based on the 2000 General Estimates System. Washington D.C.: U.S. Department of Transportation, report no. DOT-VNTSC-NHTSA02-04.

[69] The National Coroners Information System - a death and injury prevention tool. J Law Med 2000; 8:155-6. 
[70] National Injury Mortality Surveillance System. (2009). Website: (http://www.sahealthinfo.org/violence/nimss.htm , accessed 08 October, 2009)

[71] National Injury Query System. Dunedin, New Zealand: Injury Prevention Research Unit, University of Otago, 2000. (http://www.otago.ac.nz/ipru/Statistics/NIQS.html ).

[72] National Road Safety Council of Kenya (1992) Accident Statistics, 1983-1990. Nairobi: Ministry of Public Works, Government of Kenya. Onokala, P.C. (1995) The Effect of Land Use on Road Traffic Accident in Benin-City, Nigeria. Journal of Transport Studies, Vol. 1, No. 1, Pp. 34-44.

[73] Norman, R, Matzopoulos, R, Groenwald, P and Bradshaw, D. (2007). "The high burden of injuries in South Africa." Bulletin of the World Health Organization.September 2007, 85 (9). WHO. Geneva.

[74] Nwaneri (2011) General Trend of Safety and Accident Records in Nigerian Transport Sector. In: Bolade T. and Ogunsanya, A. (eds) Accident Control and Safety Measures in Mass Transit Operation in Nigeria, Ibadan University Press, P. 11.

[75] Odugbemi, O. O. (2010). Road Transportation and Tourism in Nigeria, Joja Press, Lagos.

[76] Opawole et al., (2011). General Trend of Safety and Accident Records in Nigerian Transport Sector. In: Bolade T. and Ogunsanya, A. (eds) Accident Control and Safety Measures in Mass Transit Operation in Nigeria, Ibadan University Press, P. 11.

[77] Organization for Economic Cooperation and Development Organization (2004) Managing the Environment: the Role of Economic Instrument. Paris

[78] Oluwasanmi, A.J. (1993) Road Accident Trends in Nigeria. Accident Analysis Prevention 25 (4) Pp. 485-487.

[79] Onokala, P.C. (1995) The Effect of Landuse on Road Traffic Accident in BeninCity, Nigeria. Journal of Transport Studies, Vol. 1, No. 1, Pp. 34-44.

[80] Oyeyemi (2003) Road Accident Trends in Nigeria. Accident Analysis Prevention 25 (4) Pp. 485-487.

[81] Ozanne-Smith, J., Ashby, K., Stathakis, V., et al. (2005) A decade of Victorian injury surveillance. In: Hazard. 40th ed. Victoria, Australia: Victorian Injury Surveillance and Applied Research Function, Monash University Accident Research Centre, 1999:1-9. (http://www.general.monash.edu.au/muarc/hazard/haz40.pdf).

[82] Peden, M., Toroyan, T. Counting road traffic deaths and injuries: poor data should not detract from doing something! Ann Emerg Med; 46: 158-60

[83] Phillips, M.R, Li, X., Zhang, Y. (2002) Suicide rates in China, 1995-99. Lancet; 359:83540. 
[84] Quigley M, Chandramohan D, Setel P, et al. (2000) Validity of data-derived algorithms for ascertaining causes of adult death in two African sites using verbal autopsy. Trop Med Int Health; 5:33-9.

[85] Rauscher S., Messner G., Baur P., Augenstein J., Digges K., Perdeck E., Bahouth G., and Pieske O. (2009) Enhanced Automatic Collision Notification System- Improved Rescue Care Due To Injury Prediction- First Field Experience.

[86] Ross, A. Baguley, C. Hills, V. Mchonald, M. and Silcock, d. (1991) Towards Safer Roads in Developing Countries: A guide for Planners and Engineers. Crow Thorne, U.K.; Transport Research laboratories.

[87] Santikarn C, Punyaratabandhu P, Podhipak A, et al. (1999) The establishment of injury surveillance in Thailand. Int J Consumer Product Saf; 6:133-43.

[88] Simsion and Witt (2005). Automotive Collision Avoidance System Field Operational Test: Warning Cue Implementation Summary Report. National Highway Transportation Safety Administration Report No. DOT HS 809462.

[89] Scarfone, Karen; Mell, Peter (2007). "Guide to Intrusion Detection and Prevention Systems (IDPS)". Computer Security Resource Center (National Institute of Standards and Technology) (800-94).

[90] Short, Nicholas, M. (2009) "Remote Sensing Tutorial." U.S. National Aeronautics and Space Administration (NASA). Greenbelt, MD.

[91] Smith, G.S, Langley J.D. (1998) Drowning surveillance: how well do E-codes identify submersion fatalities? Inj Prev; 4:135-9.

[92] Stansfield, S.K.; Smith, J.S. and McGreevey, W.P. (1992) Injury. In Diseases Priorities in Developing Countries. (eds) Jamison, D.T. and Mosley, W.H. World Bank, Oxford University Press, London, Pp. 609 -633.

[93] Stauffer, C. and Grimson, W. E., (1999). "Adaptive background mixture models for real-time tracking," in Proc. CVPR, June 1999, pp. 246-252.

[94] Steenkamp, M., Cripps, R. (2001) Child injuries due to falls. Canberra, Australia: Australian Institute of Health and Welfare,. (Injury research and statistics series, no. 7) (AlHW catalogue no. INJCAT (http://www.nisu.flinders.edu.au/pubs/reports/2001/falls injcat37.pdf).

[95] Steenkamp, M., Harrison, J.E. (2001) Suicide and hospitalised self-harm in Australia. Canberra, Australia: Australian Institute of Health and Welfare. (Injury research and statistics series, no. 1) (AIHW catalogue no. INJCAT 30).

[96] Taket, A. (1986) Accident Mortality in Children, Adolescence and Young Adults. World Health Statistics Quarterly, 39:232-256. 
[97] Transport and Research Laboratory (1999) Towards Safer Roads in Developing Countries, TRL, Crowthorne, U.K.

[98] Verma, M., Lange, R., and McGarry, D. (2007) A Study Of US Crash Statistics From Automated Crash Notification Data.

[99] Watson, W.L, Ozanne-Smith, J. (2000) Injury surveillance in Victoria, Australia: developing comprehensive injury incidence estimates. Accid Anal Prev;32:277-86.

[100] West and Fowler (2003). ) Road accidents and traffic flows: An econometric investigation. In Economica 67, pp 101-21.

[101] White Jules, Chris Thompson, Hamilton Turner, Brian Dougherty, and Douglas C. Schmidt (2008), WreckWatch: Automatic Traffic Accident Detection and Notification with Smartphones. Journal of Mobile Networks and Applications.

[102] Witten, I. H. and Frank E. (2000). Data Mining: practical machine learning tools and techniques with java implementations. San-Francisco, Morgan Kaufmann publishers.

[103] World Bank (1990) "Road Safety Problem in the Third World". The Urban Edge. Vol. 14, No. 1.

[104] World Bank (2004): Development Practice: Sustainable Transport Priorities for Policy Reform Chapter 3, Washington D. C.

[105] World Health Organisation (1984) Road Traffic Accidents in Developing Countries, Geneva: WHO, TRS 703

[106] World Health Organisation (1989) Analysis of Achievements of Traffic Safety in Industrialised and Developed Countries.

[107] WHO (2009). Global Status Report on Road Safety: Time for Action. Geneva. World Health Organisation www.who.int/violence injury prevention/road safety status/2009

[108] World Health Organisation (1984) Road Traffic Accidents in Developing Countries, Geneva: WHO, TRS 703

[109] Wrona, F. J.; Cash, K. J., (1996), "The ecosystem approach to environmental assessment: moving from theory to practice." Journal of Aquatic Ecosystem Health. Kluwer Academic Publishers, ISSN 0925-1014 